\title{
A carta náutica de Piri Reis (Piri Reis Haritasi), $1513^{1}$
}

\begin{abstract}
Max Justo Guedes ${ }^{2}$
RESUMO: Piri Reis, almirante otomano, elaborou sua carta partindo de conhecimentos já amplamente divulgados no Mediterrâneo e de novidades trazidas pelas navegações portuguesas. $\bigcirc$ artigo apresenta as fontes utilizadas para confeccionar o mapa, minuciosamente cotejadas com outras cartas de seu tempo, trazendo à tona diferentes aspectos da prática cartográfica portuguesa no século XVI.

PALAVRAS-CHAVE: Cartas náuticas. Portulanos. Século XVI. Expedições de levantamentos da costa. Piri Reis. Toponímia.

ABSTRACT: Ottoman Admiral Piri Reis designed his nautical chart based on a body of knowledge that was already widely disseminated in the Mediterranean and on new information brought back by Portuguese navigators. This article presents the sources used to make the Piri Reis map, thoroughly quoted against other charts of its time, and reveals certain aspects of Portuguese mapmaking practices in the $16^{\text {th }}$ century.

KEYWORDS: Nautical charts. Portolan maps. 16 $6^{\text {th }}$ century. Coastal Surveying Expeditions. Piri Reis. Toponymy.
\end{abstract}

No dia 9 de novembro de 1929, o doutor Halil Etem Eldem, diretor dos Museus Nacionais da Turquia, ao relacionar as muitas peças que constituiriam o museu de arte antiga que estava sendo instalado no Palácio de Topkapi, dos antigos sultões otomanos - um belo conjunto de edifícios localizados no Sarayburnu, em Istambul -, encontrou a parte ocidental de uma carta náutica (ou carta de marear) que, provavelmente, abrangia o mundo conhecido quando de sua elaboração. Entre as muitas legendas nela espalhadas, uma registra: "A presente carta foi desenhada no mês de muharrem 919 (isto é, entre 9 de março e 7 de abril de 1513 ) em Gelibolu [Galípoli, nos Dardanelos, próximo ao Mar de Marmara] por Piri Reis Ibn Hadii Mehmet, conhecido como sobrinho de Kemal Reis"3.

\begin{abstract}
1. Esse texto é uma adaptação da conferência The 1513 Map of Piri Reis: An Historical Puzzle, proferida em Nova York, na Universidade de Columbia, em novembro de 1993.

2. Contra-Almirante da Marinha Brasileira. E-mail: <max justoguedes@uol.com.br>.
\end{abstract}

3. Cf. Piri Reis (1988) 
Presume-se que Muhidin Piri (depois Piri Reis), filho de Haci Mehmet, tenha nascido entre 1465 e 1470, na cidade de Gelibolu, que a geografia ocidental chama de Galípoli, porto ativo e sede de importantes estaleiros, em razão de sua privilegiada situação nos Dardanelos, saída obrigatória das esquadras turcas para o mar Egeu e, logicamente, o Mediterrâneo (Figura 1). Sobrinho de Kemal Reis - pirata, corsário e, finalmente, almirante da Marinha Otomana -, Muhidin Piri alistou-se, aos 11 anos de idade, na guarnição da nau capitânia do tio. Sob a proteção deste, e graças à sua inteligência e capacidade de observação, em pouco tempo distinguiu-se entre os demais tripulantes, notadamente pela atenção que prestava à geografia mediterrânea.

Em 1494, o Sultão Bayezid II (r. 1480-1512) convidou Kemal a ser legalmente incluído na Marinha Otomana; no seu navio estava, certamente Muhidin Piri, que, sob as ordens do tio, participara intensamente do transporte da população islâmica para a costa africana, após a queda de Granada (1492).

As atividades corsárias de Kemal Reis intensificaram-se, desde então, no Mediterrâneo Ocidental, invernando nos portos de Alger, Bizerta e Tunis.

Entre 1499 e 1502, principalmente na guerra contra a Sereníssima Senhoria de Veneza, tendo Kemal Reis como comandante-em-chefe da Marinha Otomana, Piri Reis assumiu o comando de uma esquadrilha e continuou a capitanear esquadras até o falecimento (em combate, 1511 ) de Kemal Reis. Piri Reis então decidiu retirar-se para Gelibolu, onde deu inicio aos seus trabalhos cartográficos, dos quais é conhecida a parte ocidental da carta náutica de 1513; também deve ter iniciado ou consolidado suas notas sobre o livro náutico e o roteiro ilustrado que, alguns anos mais tarde, redigiria com o titulo de Kitab-i bahriye ${ }^{4}$.

Em 1516-1517, Selim I (r. 1512-1520) iniciou sua campanha contra Qānsawh, o sultão mameluco do Egito, derrotando-o em Maj Dabiq; e, no Cairo, bateu Tūman-bāy, escravo de Qānsawh, que se tornara sultão; foram, então, incorporados ao Império Otomano a Síria, a Palestina, o Egito e Hijāz Uabal al Hijāz), tornando-se o sultão otomano protetor do Islam e guardião de Meca, Medina e Jerusalém. Nestas campanhas, Piri Reis assumiu o comando de uma esquadra e esteve às ordens de Cafer-bey na tomada de Alexandria.

No Egito, Piri Reis teve oportunidade de mostrar ao Sultão Selim I sua carta náutica de 1513.

Com o falecimento de Selim I, tornou-se sultão seu filho Süleyman. Nascera em Trebizonda (1494) e, até 1512, exercera cargos de chefia; transferido para Istambul, durante as campanhas paternas, exerceu a regência até $1 \cong$ de outubro de 1520, quando assumiu o sultanato, tornando-se Supremo Governante do Império, Comandante-em-Chefe das Forças Armadas e Protetor do Islam. Era assistido pelo Divan-i Hümayun, isto é, o Conselho de Ministros, sendo o grão-vizir a autoridade executiva principal.

Em 1523, Piri Reis participou, como seria natural, da campanha de Rodes; já então estava trabalhando no Bahriye. Prontamente, o Grão-Vizir lbrahim Pasa percebeu sua importância em (1524), incentivando Piri a dar-lhe a forma de livro e copiá-lo apropriadamente. Foi assim o notável roteiro apresentado a 


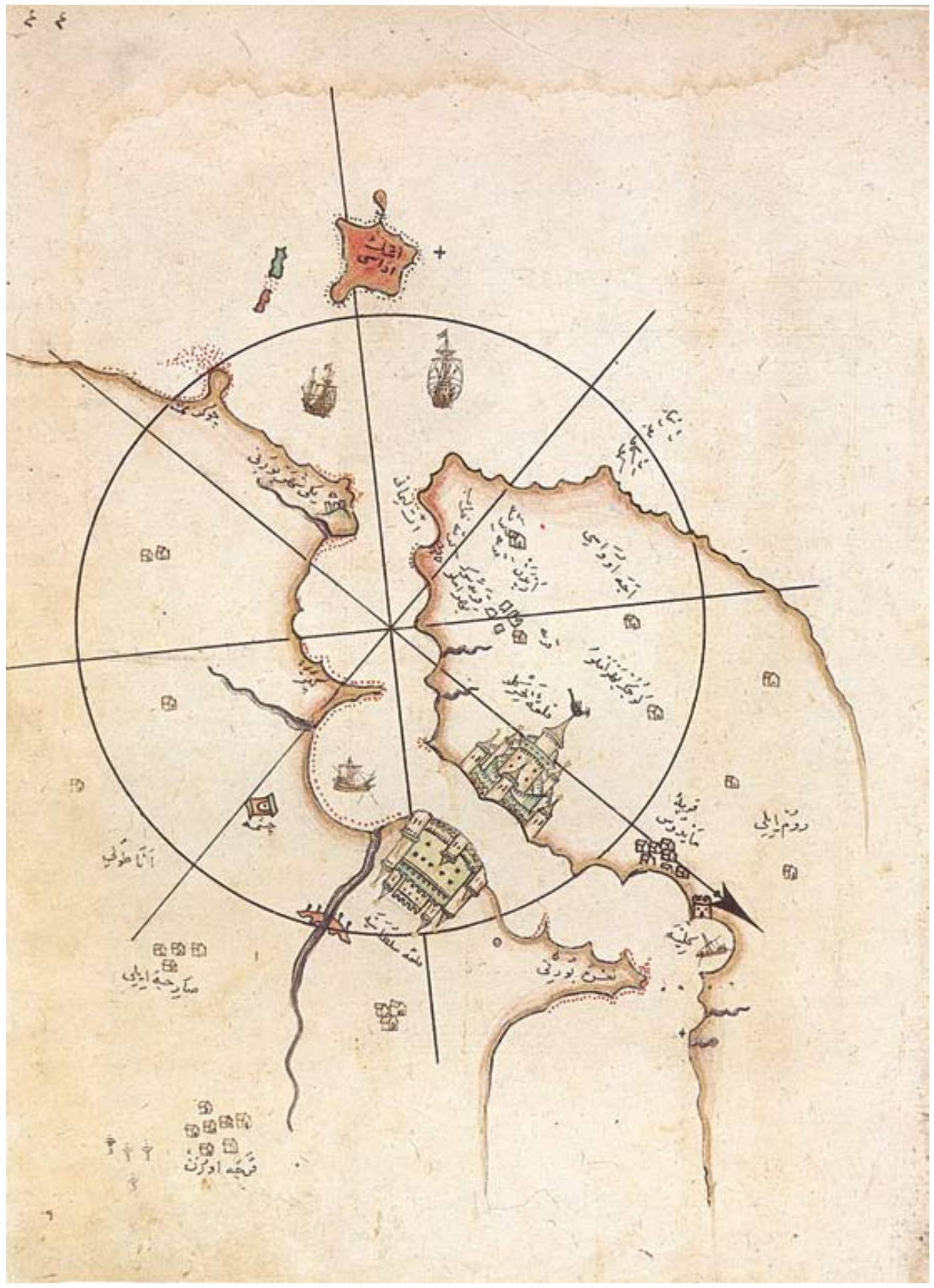

Figura 1 - Destaque para Canakkale e o estreito de Dardanelos no mapa Kitab-i bahriye (1521). Piri Reis. Istambul, Museu-Palácio de Topkapi. 
5. Atualmente na Biblioteca Nacional de Paris.

6. Ver o volume 6 dos Portugaliae monumenta cartographica, de Armando Cortesão.
Süleyman no ano 933 (1526 A.D.). É natural que as 215 cartas do manuscrito tenham sido de sua autoria, mas o texto foi copiado por excelente calígrafo. Dois anos depois outra vez em Gelibolu, (935 do calendário islâmico), elaborou Piri a segunda de suas cartas de marear hoje conhecidas; ela abrange parte do Atlântico Norte $\left(25^{\circ} \mathrm{W}\right.$ a $90^{\circ} \mathrm{W}$ e $65^{\circ} \mathrm{N}$ a $10^{\circ} \mathrm{N}$, aproximadamente); foi feita em pele de camelo e mede $0,68 \mathrm{~m} \times 0,69 \mathrm{~m}$. Como é natural, o desenho das costas e ilhas é bem mais acurado que o da carta de 1513.

Em 1547, foi Piri Reis designado para comandar o Hind Beylerbeyligi ou Hind Kapitanligi, criado em 1525 para enfrentar a forte presença portuguesa no mar Vermelho, mar da Arábia, oceano Índico e golfo Pérsico; após alguns sucessos iniciais (tomou Aden naquele mesmo ano; e Mascate em 1551), o velho almirante velejou, em 1552, para a sua última campanha, visando a expulsar as esquadras portuguesas do estreito de Ormuz e golfo Pérsico. Embora havendo conseguido levantar-o cerco de Ormuz (Jazirwh-ye-Hormoz), houve problemas em Basra (Al-Basrah), e Piri Reis retornou ao Cairo com apenas duas de suas 30 galés (1553); lá, foi acusado de abandonar seus comandados por haver sido subornado, pelo que foi o grande nauta decapitado no ano seguinte. Assim é a vida!

A Marinha Otomana, pelo menos até o aparecimento das esquadras portuguesas no oceano Índico e mares adjacentes, era essencialmente mediterrânea, limitando-se seus corsários, a pequenas incursões no Atlântico, sempre próximas às Colunas de Hércules (Gibraltar). Não tinham, portanto, ao contrário de seus inimigos peninsulares (notadamente os portugueses), necessidade de utilizar outros métodos de navegar que aqueles que os marinheiros daquele mar vinham usando há séculos e que se estendia longitudinalmente, permitindo que as rotas se fizessem próximas às costas.

O mapa de 1513 traduz perfeitamente isto, obedecendo ao que venho chamando "o princípio das necessidades satisfeitas", para explicar a falta de interesse dos navegadores em buscar novos métodos de navegar enquanto aqueles a que já se tenham habituado lhes servem.

Esta a razão que levou Piri Reis a desenhar seu mapa de 1513 segundo os princípios de construção que genoveses, venezianos e catalães vinham utilizando, pelo menos, desde a segunda metade do século XIII, sendo o mais antigo exemplo hoje conhecido a famosa Carta Pisana (ca. 1300) . Os rumos da agulha de marear e as distâncias estimadas entre os diversos acidentes costeiros eram os elementos essenciais de que se serviam os cartógrafos, sendo os perigos e as sondas obtidas com prumo e sondareza (corda graduada para medir profundidades marítimas). Era-thes dispensável, em razão da forma do Mediterrâneo, a navegação por alturas e, por isso, desnecessário o traçado da Equinocial, trópicos e meridiano graduado em graus, conforme os cartógrafos portugueses já faziam desde, pelo menos, ca. 1500 (carta portuguesa anônima, da Bayerische Staatsbibliothek, de Munique) ${ }^{6}$.

Subsistindo apenas a parte ocidental do mapa de Piri Reis $10,60 \mathrm{~m} x$ $0,85 \mathrm{~m}$ ), hoje é impossível saber-se a totalidade dos territórios por ele abrangidos (Figura 2). Provavelmente foi construído a partir de "rosa dos rumos ou ventos", 


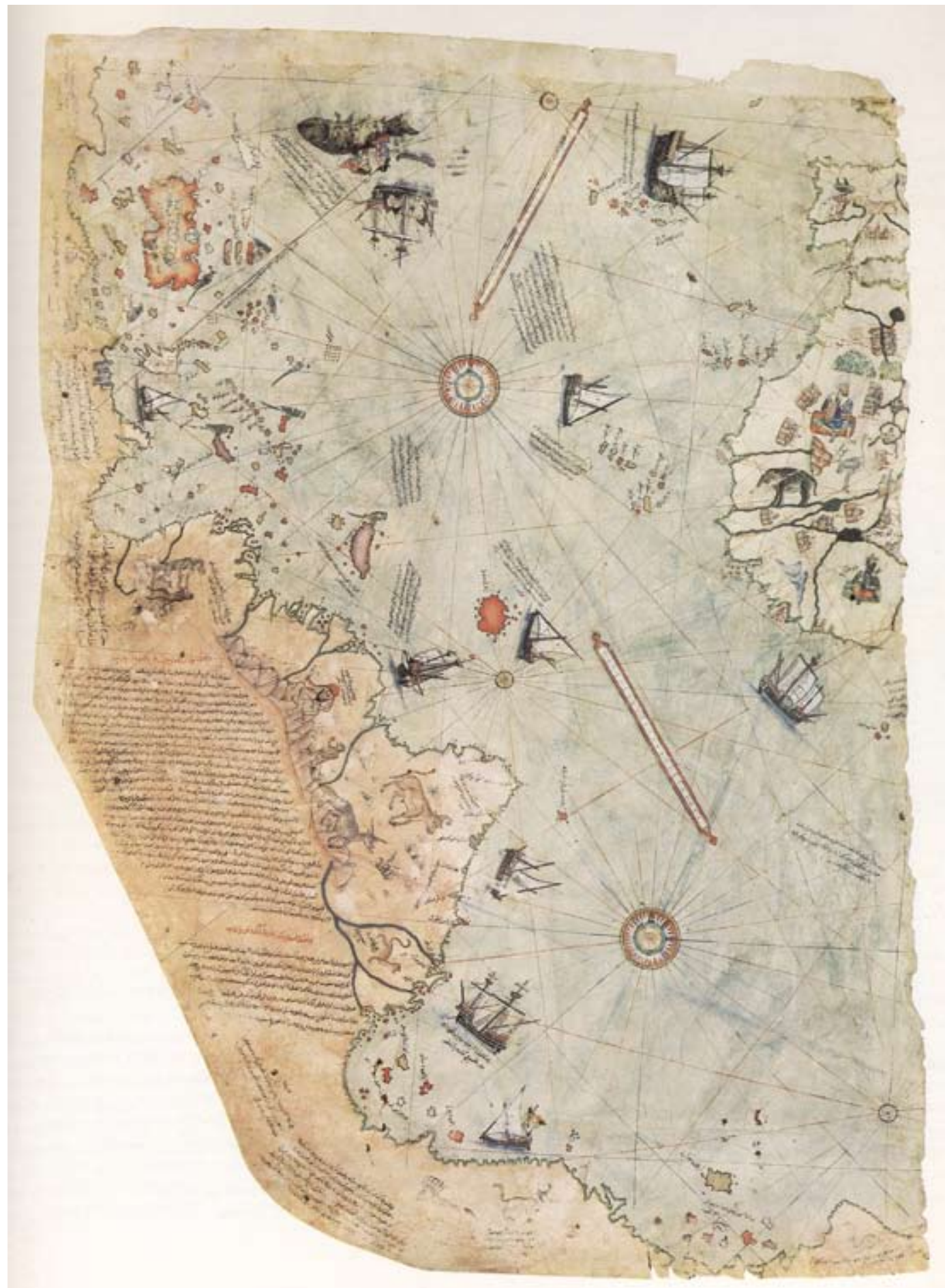

Figura 2 - Fragmento do mapa de 1513. Piri Reis (Muhiddin Piri), Istambul. Fac-símile colorido do original manuscrito em pergaminho. Mapoteca do Itamaraty, Rio de Janeiro. 
7. Piri Reis (1988, v. 1 , p. 87).

8. A exposição no Metropolitan Museum of Art, em Nova York, teve lugar de 4.10.1987 a 17.1.1988. Quanto ao catálogo, ver Esin Atıl (1987).

9. Eles constam do Acaib el Mablukat [Maravilhas da criação], de el-Kazvini, cópias quatrocentistas de Mamluk ou Akkoyunlu. pintada no meio do mapa, conforme o próprio Piri Reis explicou no Kitab-i Bahriye com 16 outras no encontro de 16 linhas de rumo com grande circunferência traçada concentricamente com a rosa central. Na seqüência, uniu o cartógrafo os 16 rumos de cada rosa subsidiária às demais, com a particularidade de desenhar as rosas dos pontos cardeais e colaterais (ao menos as que figuram no pedaço da carta subsistente) com 32 rumos.

Embora no Kitab-i Bahriye Piri Reis mostre conhecer a usual convenção de cores dos rumos, negro para os oito principais (ventos inteiros), verde para as oito meias partidas e vermelho para as 16 quartas, na edição fac-símile de 1988, esta convenção não foi respeitada, provavelmente por desconhecimento de quem a elaborou, e os ventos inteiros e as meias partidas foram desenhadas em verde e as quartas em vermelho. Note-se que, no fac-símile, há falta de vários rumos, o que, me parece, não ocorre no original, na única vez que o vi, exposto no The Metropolitan Museum of Art, Nova lorque, na mostra The Age of Sultan Süleyman the Magnificent, em janeiro de $1988^{\circ}$.

Dois petipés lançados sobre o Atlântico, o primeiro ao largo dos Açores, o outro a meio, entre o saliente do nordeste brasileiro e a costa africana, permitem a medida de distâncias na carta.

Que Piri Reis conhecia a divisória de Tordesilhas comprova-o a legenda colocada a oeste do Arquipélago de Cabo Verde, em distância aproximada daquela onde deveria ser traçada a linha divisória; no entanto, o cartógrafo estava mal informado sobre a origem de contagem dela, pois afirma estar traçada "a 2.000 milhas a oeste do estreito de Ceuta"; obviamente, o acerto do traçado provém do protótipo português ou castelhano que utilizou.

Convém notar que Piri Reis seguiu prática habitual da época, desenhando por todo o Mar Oceano (Atlântico) múltiplas embarcações, cinco naus e cinco caravelas, todas estas de dois mastros. Diga-se que estes tipos de navios e caravelas não constam em manuscritos islâmicos; Piri Reis provavelmente copiou-os de protótipos europeus (portugueses).

Finalmente, no estudo genérico do mapa, convém lembrar que o cartógrafo manteve-se fiel às suas origens, desenhando na carta monstros, seres estranhos meio humanos, meio animais, gigantesco peixe confundido com uma itha pelos companheiros de São Brandão, tudo ao gosto oriental - lembremo-nos dos seres e animais fabulosos das narrativas de Marco Polo, Piano de Carpine, Rubruc e outros embaixadores, missionários e viajantes -sempre propenso a acreditar no fabuloso ${ }^{9}$ (Figura 3).

As fontes de Piri Reis

Ao mapa para os Sete Mares, dava confiabilidade a legenda lançada sobre o território brasileiro, pouco ao sul do Rio de Janeiro (o Sano Saneyro do mapa), informando-nos que as fontes utilizadas foram cerca de 20 cartas náuticas e mapas-múndi (8 mapas), denominados Jaferiye pelos árabes. Além desses, foram 


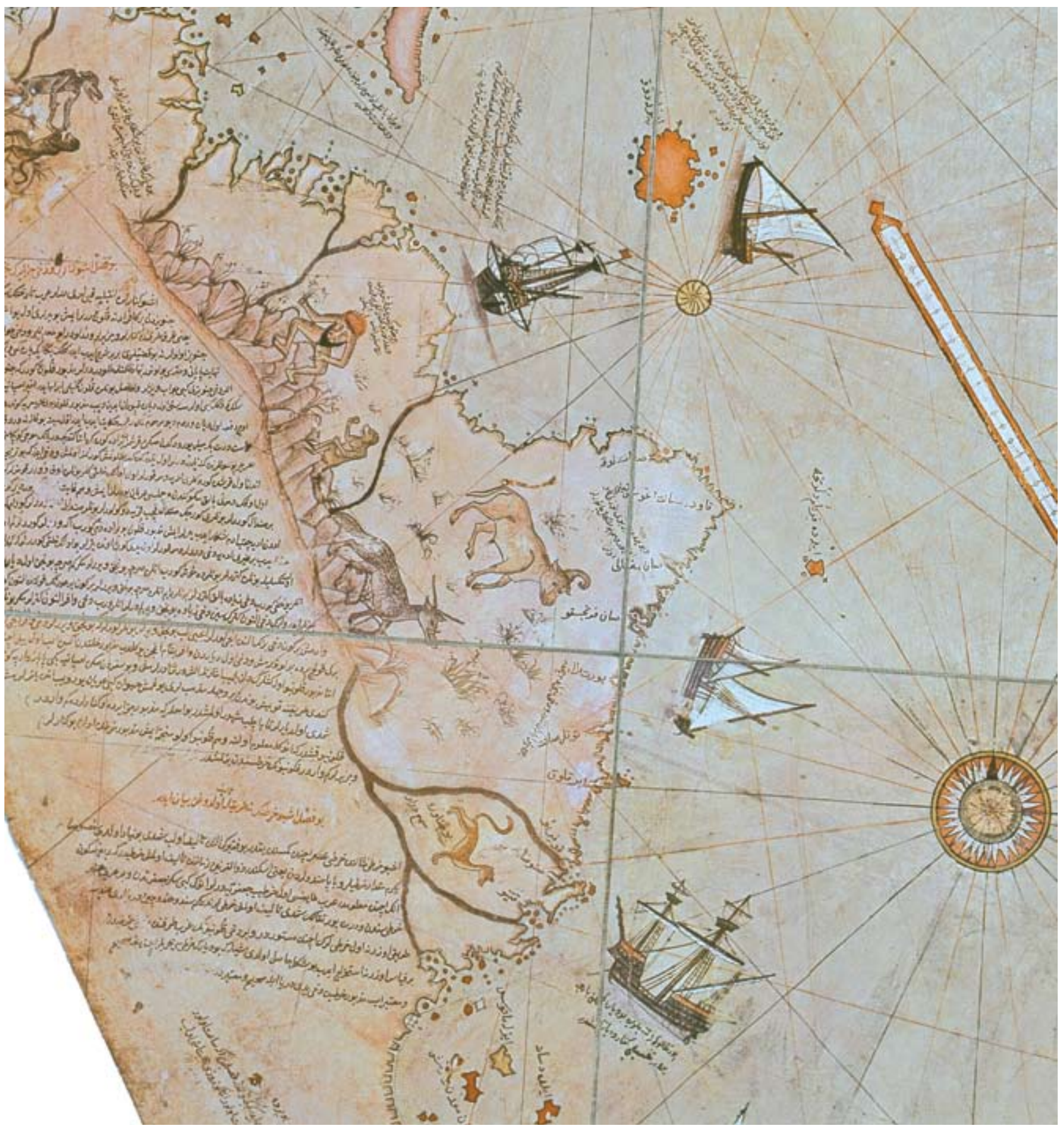

Figura 3 - Destaque para costa litorânea da América do Sul, com embarcações e monstros. Na lateral direita veja-se o petipé representado parcialmente. Fragmento do mapa de 1513, Piri Reis (Muhiddin Piri), Istambul. Fac-símile colorido do original manuscrito em pergaminho. Mapoteca do ltamaraty, Rio de Janeiro. 
consultados, também, mais um mapa árabe do Hind (Índia) e outros, feitos por quatro portugueses, que mostravam "Hind, Sind e China geometricamente desenhados", e uma carta da região ocidental, de autoria de Cristóvão Colombo.

Hoje, perdida a parte do mapa relativa ao Oriente - perda verdadeiramente lastimável para a comprovação de quais os conhecimentos que os portugueses já possuíam do Extremo Oriente -, vejamos o que se pode deduzir da análise das regiões ribeirinhas do Atlântico.

Deixando de lado a Península Ibérica e o litoral africano, de há muito padronizados na cartografia européia, examinemos os três grandes arquipélagos que, no século anterior, haviam entrado na órbita da colonização luso-castelhana.

Os arquipélagos do Atlântico oriental

$$
\text { a) Os Açores }
$$

Quadro 1 - Toponímia dos Açores, em Piri Reis e na atualidade

\begin{tabular}{|l|l|l|}
\multicolumn{1}{|c|}{ Piri Reis } & \multicolumn{1}{c|}{ Toponímia Atual } & \multicolumn{1}{c}{ Observações } \\
\hline- & Corvo (?) & \\
\hline Isle Flores & Flores & \\
\hline Finoci & Graciosa (?) & Deslocada e fora de proporção \\
\hline Firgal & Faial (?) & \\
\hline Kopis & Terceira (?) & \\
\hline- & São Jorge (?) & \\
\hline- & Faial (?) & \\
\hline Eviko & Pico & \\
\hline San Mikal & São Miguel \\
\hline Santa Marya & Santa Maria \\
\hline
\end{tabular}

$\bigcirc$ Quadro 1 permite comprovar que, para desenhar e copiar a toponímia do arquipélago, muito provavelmente não foram usados padrões portugueses; além disto, o quadro demonstra a tremenda dificuldade de Piri Reis em manejar os idiomas peninsulares, surgindo dai incríveis deformações nos nomes geográficos: Firgal $=$ Faial, Eviko $=$ Pico e San Mikal = São Miguel.

Legenda de Piri Reis, posicionada ao norte dos Açores, informa que seu descobrimento fora casualmente efetuado por embarcação genovesa vinda de Flandres e para ali impelida por tempestade, o que talvez nos permita suspeitar haver o cartógrafo utilizado padrão genovês para o Atlântico Oriental, suspeita que será reforçada adiante, conforme será mostrado.

b) As Canárias 
Quadro 2 - Toponímia das Canárias, em Piri Reis e na atualidade

10. Cf. Cristovão Colombo (1899).

\begin{tabular}{|l|l|l|}
\multicolumn{1}{c|}{ Piri Reis } & \multicolumn{1}{c|}{ Toponímia Atual } & \multicolumn{1}{c|}{ Observações } \\
\hline Lenserto & Lanzarote & \\
\hline Ventora & Fuerteventura & \\
\hline Hi de Kanarie & Gran Canaria & \\
\hline Elferno & Tenerife & \\
\hline Gomara & Gomera & Posições relativas trocadas \\
\hline Palme & La Palma & \\
\hline He Fero & Hierro (Ferro) & \\
\hline
\end{tabular}

Quadro 2 possibilita verificar que as informações de Piri Reis sobre o arquipélago canarino eram bem superiores às que possuía sobre os Açores. Não só a deturpação da toponímia é bem menor, como o posicionamento das ithas razoavelmente correto, se excetuarmos a troca de posições entre La Palma e Hierro.

A que (ou a quem) atribuir tal diferença? Só nos ocorre creditá-la à carta de autoria de Cristóvão Colombo, mencionada como fonte, o que confirma o dizer do cartógrafo turco.

A semelhança entre o desenho do arquipélago em Piri Reis e em Juan de la Cosa (1500) endossa tal suposição, pois não deveriam ser muito discrepantes as idéias de Colombo e as de seu "maestro de hacer cartas" 10.

c) $\bigcirc$ Arquipélago de Cabo Verde

Quadro 3 -Toponímia do Arquipélago de Cabo Verde, em Piri Reis e na atualidade

\begin{tabular}{|c|c|c|c|}
\hline Piri Reis & Toponímia Atual & & Observações \\
\hline Emaye & Maio & \multirow{5}{*}{$\begin{array}{l}\text { Grupo } \\
\text { Oriental }\end{array}$} & \multirow{5}{*}{$\begin{array}{l}\text { As cinco do grupo oriental foram } \\
\text { as primeiramente descobertas }\end{array}$} \\
\hline Bomiste & Boavista & & \\
\hline Dösalo & Sal & & \\
\hline Sigogo & Santiago & & \\
\hline Rosigo & Fogo & & \\
\hline Brava & Brava & \multirow{5}{*}{$\begin{array}{l}\text { Grupo } \\
\text { Ocidental }\end{array}$} & \multirow{5}{*}{ Falta a Itha de S. Vicente } \\
\hline Sen Nikola & São Nicolau & & \\
\hline |leçi & Santa Luzia & & \\
\hline Ilebiyanco & Ilheu Branco & & \\
\hline Sen Tiyono & Santo Antão & & \\
\hline
\end{tabular}


11. Ver Luís de Cadamosto (1948).

12. Ver Joaquim Barradas de Carvalho (1991, p. 23-24).

13. Ver o sexto volume de Portugalia Monumenta Cartographica, de Armando Cortesao e Avelino Mota Teixeira.

14. Ver em Joaquim Romero Magalhães e Susana Münch Miranda (1999).
O exame do quadro 3 comprova que, neste caso, não foi a carta de Colombo a fonte do turco, tal a deturpação da toponímia e, se comparado ao de Juan de la Cosa (1500), a diferença do desenho. Como na cartografia dos Açores - embora aqui, muito menos evidente - também parece que a utilização de padrão português foi indireta, suspeita reforçada por legenda lançada pouco a oeste do conjunto de ilhas, junto à caravela ali desenhada: "O mestre desta caravela é chamado Messire Anton o genovês, mas criou-se em Portugal. Certo dia esta caravela foi colhida por tempestade e lançada nesta itha. Ele [o mestre] encontrou aqui muito gengibre e escreveu sobre estas ilhas". Obviamente, Piri Reis utilizou-se da relação de Cadamosto ${ }^{11}$, o que identifica este Messire Anton como Antoniotto Usodimare, companheiro de Cadamosto em 1456; segundo este, as ithas do grupo oriental teriam sido descobertas quando sua caravela foi apanhada por tempestade ao largo do Cabo Branco.

Imagino, assim, que Piri Reis utilizou-se de carta genovesa, obviamente baseada em padrão português já bem superado.

\section{Continente Austral}

Ao desenhar as terras antárticas, Piri Reis nada mais fez do que ater-se à velha tradição de ser o Atlântico um mar mediterrâneo, metido entre o Ecúmeno (Europa, Ásia e África) e a quarta parte do Orbe, onde habitavam os antípodas. Para comprovar isto, basta ler-se Duarte Pacheco Pereira ${ }^{12}$ ou observar o planisfério de Lopo Homem (1519)13.

As Américas

Chegamos, finalmente, à parte verdadeiramente interessante le cartograficamente importante) do mapa de Piri Reis de 1513.

Para estudá-la apropriadamente, faz-se necessário cuidar, em separado, das ithas e da terra firme descobertas por Cristóvão Colombo entre outubro de 1492 e agosto de 1498 (1. ${ }^{a}, 2 .^{a}$ e $3 .^{a}$ viagens), e os descobrimentos de Pedro Álvares Cabral e as viagens de reconhecimento territorial que se lhes seguiram ${ }^{14}$, especialmente as capitaneadas por Gonçalo Coelho em 1501-1502 e 1503-1504.

\section{Os descobrimentos castelhanos}

A maior de todas as legendas lançadas no interior da costa norte da América do Sul por Piri Reis em seu mapa de 1513, informa aos que dele se 
utilizam a respeito das "costas e ilhas... da Antília" e de seu descobrimento, "no ano de 896 do calendário árabe", por um infiel genovês chamado Colombo ${ }^{15}$.

$\bigcirc$ texto é sumamente confuso, pois as três viagens do Almirante do Mar Oceano são misturadas indiscriminadamente, como se aí os acontecimentos tivessem ocorrido sucessivamente. Assim, aparecem o encontro com os caribes (canibais), fato da segunda viagem e o achamento das pérolas, trocadas com os indígenas guayqueri ocorrido na terceira viagem.

Obviamente, o informante espanhol, escravo de Gazi Kamal, ou foi mal compreendido ou os sofrimentos do cativeiro le sabemos que eram sumamente duros) haviam confundido sua memória.

Da mesma maneira, o mapa da "região ocidental desenhado por Colombo" ou foi cópia defeituosa da carta do genovês (sabe-se, positivamente, que ele cartografou os territórios descobertos e utilizou-se da habilidade de Juan de la Cosa para auxiliá-lo) ou a carta do Almirante do Mar Oceano estava cheia de deficiências e erros.

Quando Piri Reis transferiu-a para o seu mapa, a apresentação tornou-se possivelmente ainda mais distorcida que a do original, uma vez que, além da deformação do desenho, também a toponímia sofreu muito, como mostrado adiante.

Para tentar desembaralhar os dados do mapa e identificar as ilhas e territórios nele constantes, há que recorrer às derrotas das viagens colombinas.

\section{Primeira viagem}

Partindo das Canárias (Gomera), a esquadrilha mais famosa da história americana (Santa Maria, Pinta e Niña) foi avistar Guanahani (San Salvador), nas Bahamas, em 12 de outubro de 1492. A ilha deveria, obviamente, figurar no mapa, mas nem ela nem qualquer outra do arquipélago pode ser nele identificada, à exceção, talvez, da Fernandina (atualmente Long Island) que deve ser a lle verde, topônimo de seu cabo mais meridional.

Percorridas várias das ilhas, Colombo finalmente fez-se no rumo sul, indo aterrar, em 29 de outubro, em Bariay (p. San Salvador), na ilha de Cuba, próximo à muito conhecida Guantanamo e ao norte da Sierra Maestra. Seguindo a idéia de Colombo de haver chegado à terra firme, o mapa mostra apenas uma pontiaguda península, voltada na direção da Isle despania (Hispaniola), a Haiti dos tainos, cuja costa norte a esquadrilha percorreu entre 7 de dezembro de 1492 e 18 de janeiro de 1493, ali deixando, além do casco soçobrado da Santa Maria, 34 espanhóis que guarneceriam a torre-fortaleza de La Navidad, recordada por Piri Reis como Paksin vidad, embora muito deslocada.

Por mais estranho que pareça, alguns especialistas têm afirmado que a grande itha retangular do mapa de Piri Reis é Cuba, ignorando os topônimos ali colocados e contrariando frontalmente a certeza do genovês de ser Cuba terra firme! Das duas, uma: ou a ilha é Cuba e o padrão usado não foi o mapa de Colombo, ou, se o foi, a itha é a atual Hispaniola. 
Segunda viagem

Quadro 4 - Análise comparativa: Piris Reis, Colombo e denominação atual

\begin{tabular}{l|l|l|}
\multicolumn{1}{c|}{ Piri Reis } & \multicolumn{1}{c}{ Colombo } & \multicolumn{1}{c}{ Toponímia atual } \\
\hline Dösiyta & Dominica (3.11.1493) & Dominica \\
\hline Galanda & $\begin{array}{l}\text { Mariagalante } \\
\text { Santa Maria de Guadalupe }\end{array}$ & Marie-Galante \\
\hline Santemeroye & $\begin{array}{l}\text { (S. M. de Monserrat) } \\
\text { (S.M. La Redonda) }\end{array}$ & Guadeloupe \\
\hline Samokristo & S. Cristobal & Saba \\
\hline Kavav & (?) & \\
\hline Onze Virgens & Once Mil Virgines & Virgin Islands \\
\hline Isle Bele & Graciosa & Vieques \\
\hline
\end{tabular}

No quadro 4, é mostrado o roteiro da segunda viagem, cujo destino era a Hispaniola, que seria colonizada. Nela foram descobertas as Pequenas Antilhas (Islas de Barloviento), a partir da Dominica (3.1 1 . 1493) até ser alcançada a Hispaniola, 20 dias mais tarde.

Os acontecimentos mais notáveis desta viagem foram:

a. o encontro com os terríveis caribes, canibais que percorriam as múltiplas ilhas da região para caçar outros indígenas, engordá-los e devorá-los.

b. o descobrimento das Once Mil Virgines (Virgin Islands) e San Juan Bautista (19.1 1.93), atual Puerto Rico.

Não é difícil observar a grande deturpação do desenho de Piri Reis, mesmo se comparado ao de Juan de la Cosa.

\section{Terceira viagem}

Não menos precário é o desenho do trecho costeiro relativo ao percurso das três velas da terceira viagem de Colombo ao Novo Mundo, quando foi descoberta a Tierra Firme americana, desde a Isla de Trinidad (3 1.7.1498), reconhecido o golfo de Pária, algumas bocas do Orenoco, a península de Pária, as ithas Margarita e Alto Vela (1 5 de agosto de 1498), viagem que terminou em Santo Domingo (3 1 .8. 1498), onde Colombo foi preso pelo Governador Bobadilla e despachado para a Espanha.

Como sabemos que fez carta y pintura desta viagem, ou era ela muito deficiente ou a cópia que chegou a Piri Reis estava bastante deturpada, pois é praticamente impossível reconhecer no seu mapa os acidentes que enumeramos, especialmente a llha de Trinidad e o delta do Orenoco.

Pode-se concluir, quanto ao traçado de Piri Reis dos descobrimentos 
castelhanos: ou foi empregada cópia terrivelmente falha da carta de Cristóvão Colombo ou o desenho desta era muitíssimo precário, deixando o genovês mal como cartógrafo.

\section{2. $\bigcirc$ descobrimento do Brasil e o reconhecimento da costa}

De Lisboa, em 9 de março de 1500, velejou a armada de 13 navios (naus e caravelas) capitaneada por Pedro Álvares Cabral; em 22 de abril, um monte alto e redondo (Monte Pascoal) foi avistado e, dois dias após, a armada fundeou, algumas milhas ao norte, no Porto Seguro (hoje baía Cabrália), sendo a latitude do local calculada pelo cosmógrafo mestre Juan Faras e pilotos da capitânia e da nau de Sancho de Tovar. Utilizando o astrolábio, tomaram a altura do sol ao meio-dia e, empregando as tábuas de declinação e as regras do instrumento, acharam estar em 17오. A terra descoberta foi denominada llha de Vera Cruz e logo tornou-se a Terra de Santa Cruz e, por fim, Brasil.

Para levar ao Reino a notícia do achamento, velejou o navio dos mantimentos, capitaneado por Gaspar de Lemos, que, provavelmente, reconheceu a costa até sua inflexão para noroeste, como está demonstrado no desenho original do famoso planisfério dito Cantino (1502), o primeiro a mostrar a terra descoberta, ficando o topônimo Cabo de San Jorge primitivo muito longe de terra.

Tão logo foi o descobrimento sabido em Lisboa, D. Manuel fez armar esquadrilha para reconhecer a nova terra. Os melhores estudos apontam Gaspar Coelho como seu capitão-mor; Amerigo Vespucci ${ }^{16}$, que havia passado do serviço espanhol para o português, participou da expedição e foi autor das únicas notícias hoje existentes sobre as explorações feitas por Gonçalo Coelho.

Cabe aqui lembrar que se desconhece a função do florentino a bordo da esquadrilha; também ignoram-se os conhecimentos que então possuíam sobre a nova forma de navegar (usando a altura do sol em sua passagem meridiana - altura do sol ao meio dia - medida com o astrolábio náutico que os portugueses haviam criado e estavam principiando a empregar no mar).

As notícias que Vespucci deu das ditas explorações estão reunidas em duas cartas manuscritas e duas outras impressas:

a. carta manuscrita enviada de Lisboa a Lorenzo di Pier Francesco de Medicci (duas cópias conhecidas).

b. fragmento de carta a Lorenzo de Medicci (1502?), que o copista atribuiu a Vespucci.

c. relação impressa Mundus Novus, baseada em carta de Vespucci a Pier Francesco. Primeira edição positivamente datada, Augsburg, 1504, ed. Johannes Otmar Vindelice, texto em latim.

d. relação impressa, em italiano, intitulada Lettera lendereçada a Piero Soderine). Sem data de edição ( 1505 ou 1506, por Gian Stefano di Carlo di Pavia). São conhecidas duas cópias manuscritas com 
a data de 4 de setembro de 1504, além de transcrição do século XVIII.

Como pode ser verificado no quadro que se segue, a comparação dos quatro documentos não permite conclusões positivas acerca da derrota costeira da expedição, pois as informações extraídas deles diferem consideravelmente entre si.

Quadro 5 - Comparação dos quatro documentos de Amerigo Vespucci

\begin{tabular}{|c|c|c|c|c|}
\hline Eventos & $\begin{array}{l}\text { Lisboa } \\
\text { (1502) }\end{array}$ & Fragm. & Mundus Novus & Lettera \\
\hline Partida de Lisboa & - & - & 14.5 .1501 & 10.5 .1501 \\
\hline Passagem pelas Canárias & - & - & 16.5 & 16.5 \\
\hline Chegada ao Cabo Verde & & & 21 ou 24.05 & 3.6 \\
\hline $\begin{array}{l}\text { Permanência no } \\
\text { Cabo Verde }\end{array}$ & & & (1 1dias) & (11 dias) \\
\hline Partida do Cabo Verde & & & 4.6 ou 1.6 & $(14.6)$ \\
\hline Travessia do Atlântico & & $64 \mathrm{~d}$ & $\begin{array}{l}167 \text { d. ou } \\
2 m . \text { e 3d.) }\end{array}$ & $67 \mathrm{~d}$ \\
\hline Léguas de distância & & & 700 & 700 \\
\hline Chegada ao Brasil & & & 7.8 & 17.8 \\
\hline Local de arribada & & & & $5 \div 5$ \\
\hline $\begin{array}{l}\text { Distância (ao cabo de } \\
\text { Santo Agostinho) }\end{array}$ & & & 300 léguas & 150 léguas \\
\hline Último ponto visitado & & $32 \div 5$ & & ca. $26^{\circ}=5$ \\
\hline Distância percorrida até ele & $\begin{array}{l}800 \text { léguas } \\
\text { desde a } \\
\text { aterragem }\end{array}$ & & 600 léguas & 600 léguas \\
\hline Latitude extrema alcançada & $50^{\circ}=$ & $\begin{array}{l}50 \div S \\
\text { (no mar) }\end{array}$ & $50^{\circ} S$ & $\begin{array}{l}52 \text { ㅇ S } \\
\text { (no mar) }\end{array}$ \\
\hline Chegada a Serra Leoa & & $16 \mathrm{~m}$ & & 10.5 .1502 \\
\hline Chegada a Lisboa & & & 7.9 & 22.7 \\
\hline
\end{tabular}

O único auxílio possível para buscar a solução do problema é a cartografia coeva. Para utilizá-la, faz-se absolutamente necessária a mais completa e correta análise das principais cartas e mapas do período em causa. Aqui, o mapa de Piri Reis de 1513 assume capital importância, como tentarei mostrar. 
Entre as cartas elaboradas de 1500 a 1513 que examinei (cerca de 40), seis foram selecionadas para comparação:

a. Nicoló de Caverio (Nicolay de Caverio iannensis), planisfério de 1503-1504, Paris.

b. Vesconte di Maggiolo (Maiollo.), de 1504, Fano.

c. Carta atlântica denominada Kunstmann IIII7, c. 1506, desaparecida, durante a Segunda Guerra Mundial, do Hauptconservatorium der Armee, Munique.

d. Johannes Ruysch, planisfério inserido na edição do Ptolomeu, Roma, 1508.

e. Carta da costa do Brasil, de Francisco Rodrigues, c. 1513, no Livro de Francisco Rodrigues, Paris.

f. Mapa de Piri Reis, de 1513.

Como pode ser facilmente verificado, todas estas cartas e mapas mostram a costa brasileira entre o ponto de aterragem da esquadrilha de Gonçalo Coelho (São Roque, com as suas diferentes grafias) e uma sequência de baías e angras, com múltiplas ilhas, que se seguem a um cabo que protubera para leste.

Não muito longe daquela primeira aterragem, o desenho costeiro apresenta seu ponto extremo leste (Cabo de Sancta +, Cauo de santa croxe ou Cabo de Stº Agostinho, isto é, o Kav de Santa Agostini, de Piri Reis).

Diversos especialistas têm utilizado a escala de latitudes do planisfério de Nicoló de Caverio, c. 1504, para demonstrar que a expedição de 1501-1502, depois de o comando haver sido transferido para Amerigo Vespucci - o que parece sumamente improvável pelo regime adotado pela Coroa portuguesa para suas esquadras e esquadrilhas, avançou ao longo da costa até os $50^{\circ} \mathrm{S}$ - como é afirmado na Mundus Novus, porque o último topônimo registrado, Rio de cananor, é posicionado em $36^{\circ} \mathrm{S}$.

Trata-se, no mínimo, de tremenda falta de compreensão do desenho costeiro, porque facilmente se pode verificar que acidentes conspícuos e por demais conhecidos como a baie de tuti li santi é posicionada em 17오, quatro graus além da sua real posição, Porto Seguro está em 2020'S, sendo a latitude correta $16^{\circ} 26^{\prime} \mathrm{S}$, Mont Passqual é colocado em $23^{\circ} \mathrm{S}$, com erro de seis graus e a baía de reis situa-se em $31^{\circ}$ S, erro de circa de oito graus.

Obviamente, os cartógrafos italianos /o autor anônimo da Kunstmann II18, mais Caverio e Maggiolo não tiveram posições observadas para corrigir suas cartas e, por outro lado, não compreenderam a orientação da costa diretamente para oeste após o Cabo Frio). Mesmo o autor anônimo da carta portuguesa Kunstmann $\mid I^{19}$, ca. 1506, embora apresentando melhor orientação desta parte da costa (Cabo Frio até rio de cananea) colocou cananea alguns graus ao sul do dito cabo, posição irrealista, conforme sabemos todos.
17. Trata-se de Frederich Kunstmann (1859).

18. Idem.

19. Idem. 
O mapa de Piri Reis e a costa brasileira

Quadro 6 - Toponímia da costa brasileira em Piri Reis e na atualidade

\begin{tabular}{ll|l|l}
\multicolumn{1}{c|}{ Piri Reis } & \multicolumn{1}{c|}{ Toponímia Atual } & \multicolumn{1}{c}{ Observações } \\
ile de Firnan de Lonce & Fernando de Noronha & itha de \\
\hline Santalo-ka & São Roque & cabo de \\
\hline Kav de Santa Agostini & Santo Agostinho & cabo de \\
\hline San Megale & São Miguel & rio de \\
\hline Totel Sante & Todos os Santos & baía de \\
\hline Abraklok & Abrolhos & arquipélago dos \\
\hline Kav Friyo & Cabo Frio & \\
\hline Sano Saneyro & Rio de Janeiro & \\
\hline Katino & Santo Antônio & \\
\hline
\end{tabular}

O ano de 1513 foi crucial para o correto desenho do litoral brasileiro. Naquele ano, dois importantes monumentos cartográficos foram elaborados: o mapa de Piri Reis e o chamado Livro de Francisco Rodrigues ${ }^{20}$; entre Vespucci as 26 cartas deste livro, uma mostra-nos o traçado da costa brasileira tendo ao longo dela escala de latitudes que vai dos $2^{\circ} \mathrm{S}$ até $30^{\circ} \mathrm{S}$.

O desenho costeiro de Francisco Rodrigues é muito semelhante ao de Piri Reis, o que nos autoriza considerar demonstrado que a sequência de cabos, baías e angras ao sul da Serra de Sam Tomé, mostrada nos mapas italianos, é idêntica à situada a oeste do Cabo Frio, isto é: Rio de Janeiro, Angra dos Reis, São Vicente e Cananéia.

Felizmente, pela primeira vez na cartografia brasileira, o mapa de Piri Reis registra o topônimo Rio de Janeiro (Sano Saneyro), posicionando-o muito próximo ao Cabo Frio (Kav Friyo), o que confirma a demonstração.

A conclusão final é fácil de ser alcançada: embora nada tenha inovado na História da Cartografia, o mapa de Piri Reis de 1513 é monumento da maior importância para os primórdios da cartografia das Américas, muito especialmente para a do Brasil, porquanto é fundamental para por cobro às lendas vespucianas e desenganar seus ingênuos defensores, deixando perfeitamente claro que o primeiro reconhecimento costeiro de Brasil alcançou unicamente as proximidades da Cananéia, onde a excelente estima de Gonçalo Coelho e seus pilotos intuiu que findava o território português delimitado pela linha de Tordesilhas. A gigantesca expansão que, fazendo tábua rasa do Tratado de Tordesilhas, deu ao Brasil a sua dimensão continental é outra estória. 


\section{REFERÊNCIAS}

ATIL, Esin. The Age of Sultan Süleyman the Magnificent. Catálogo. Washington, D.C.: National Gallery of Art, 1987.

CADAMOSTO, Luís de. Viagens de Luis de Cadamnosto e Pedro de Sintra. Trad. de F. Machado e D. Peres. Lisboa: [s. n.], 1948.

CARVALHO, Joaquim Barradas de. As fontes de Duarte Pacheco Pereira no Esmeraldo de Situ Orbis. Lisboa: Serviço de Educação-Fundação Calouste Gulbenkian, 1991.

COLOMBO, Cristovão. "Lettera raríssima" de Christophe Colomb sur la découverte de la terre-firme. Accompagnée l'itinéraire de Diego de Porras et d'une partie de la Relation de Diego Méndez. Paris: Garnis; Angers: A. Burdin,1899.

CORTESÃO, Armando. Portugaliae monumenta cartographica. Lisboa: Comissão Executiva das Comemorações do V Centenário da Morte do Infante D. Henrique, 1960

GARCIA, José Manuel (Org.). O Livro de Francisco Rodrigues. O Primeiro Atlas do Mundo Moderno. Porto: Editora da Universidade do Porto, 2008

KUNSTMANN, Friedrich. Atlas zur Entdeckungsgeschichte Amerikas... München: A. Asher, 1859.

MAGALHÃES, Joaquim Romero; MIRANDA, Susana Münch (Ed.). Os primeiros 14 documentos relativos à Armada de Pedro Álvares Cabral. Lisboa: Comissão Nacional para as Comemorações dos Descobrimentos Portugueses, 1999.

PEREIRA, Duarte Pacheco. Esmeraldo de Situ Orbis. Ed. Damião Peres. Lisboa: Academia Portuguesa de História, 1954.

REIS, Piri (Hadji Muhammad). Kitab-i babriye (1521), Istambul: Historical Research Foundation; Istanbul Research Center, 1988.

VESPUCCI, Amerigo. Cartas de viaje. Intr. y not. Luciano Formisano. Madrid: Alianza, 1986.

Artigo apresentado em 8/2008. Aprovado em 12/2008. 